\title{
Disease-specific and general health-related quality of life in newly diagnosed prostate cancer patients: the Pros-IT CNR study
}

Angelo Porreca ${ }^{1 \dagger}$, Marianna Noale $^{2^{*}+} \mathbb{D}$, Walter Artibani ${ }^{3}$, Pier Francesco Bassi ${ }^{4}$, Filippo Bertoni ${ }^{5}$, Sergio Bracarda ${ }^{6}$, Giario Natale Conti ${ }^{7}$, Renzo Corvò ${ }^{8}$, Mauro Gacci ${ }^{9}$, Pierpaolo Graziotti ${ }^{10}$, Stefano Maria Magrini ${ }^{11}$,

Vincenzo Mirone ${ }^{12}$, Rodolfo Montironi ${ }^{13}$, Giovanni Muto ${ }^{14}$, Stefano Pecoraro ${ }^{15}$, Umberto Ricardi ${ }^{16}$, Elvio Russi ${ }^{17}$, Andrea Tubaro ${ }^{18}$, Vittorina Zagonel ${ }^{19}$, Gaetano Crepaldi ${ }^{1}$, Stefania Maggi ${ }^{1}$ and the Pros-IT CNR study group

\begin{abstract}
Background: The National Research Council (CNR) prostate cancer monitoring project in Italy (Pros-IT CNR) is an observational, prospective, ongoing, multicentre study aiming to monitor a sample of Italian males diagnosed as new cases of prostate cancer. The present study aims to present data on the quality of life at time prostate cancer is diagnosed.
\end{abstract}

Methods: One thousand seven hundred five patients were enrolled. Quality of life is evaluated at the time cancer was diagnosed and at subsequent assessments via the Italian version of the University of California Los AngelesProstate Cancer Index (UCLA-PCI) and the Short Form Health Survey (SF-12).

Results: At diagnosis, lower scores on the physical component of the SF-12 were associated to older ages, obesity and the presence of $3+$ moderate/severe comorbidities. Lower scores on the mental component were associated to younger ages, the presence of 3+ moderate/severe comorbidities and a T-score higher than one.

Urinary and bowel functions according to UCLA-PCI were generally good. Almost 5\% of the sample reported using at least one safety pad daily to control urinary loss; less than $3 \%$ reported moderate/severe problems attributable to bowel functions, and sexual function was a moderate/severe problem for 26.7\%. Diabetes, 3+ moderate/severe comorbidities, T2 or T3-T4 categories and a Gleason score of eight or more were significantly associated with lower sexual function scores at diagnosis.

Conclusions: Data collected by the Pros-IT CNR study have clarified the baseline status of newly diagnosed prostate cancer patients. A comprehensive assessment of quality of life will allow to objectively evaluate outcomes of different profile of care.

Keywords: Prostate cancer, Quality of life, Diagnosis, Pros-IT CNR study

\footnotetext{
* Correspondence: marianna.noale@in.cnr.it

${ }^{+}$Angelo Porreca and Marianna Noale contributed equally to this work.

${ }^{2}$ National Research Council (CNR), Neuroscience Institute, Aging Branch, Via

Giustiniani 2, 35128 Padova, Italy

Full list of author information is available at the end of the article
}

(c) The Author(s). 2018 Open Access This article is distributed under the terms of the Creative Commons Attribution 4.0 International License (http://creativecommons.org/licenses/by/4.0/), which permits unrestricted use, distribution, and reproduction in any medium, provided you give appropriate credit to the original author(s) and the source, provide a link to the Creative Commons license, and indicate if changes were made. The Creative Commons Public Domain Dedication waiver (http://creativecommons.org/publicdomain/zero/1.0/) applies to the data made available in this article, unless otherwise stated. 


\section{Background}

Prostate cancer was the most common cancer diagnosed in men worldwide in 2015 [1]. With the exclusion of skin cancers, it represents $20 \%$ of all malignancies diagnosed in Italian males 50 years old or older [2]. Survival rates after a prostate cancer diagnosis continue to rise; approximately $89 \%$ of Italian patients are still alive 5 years after diagnosis, with North-western regions showing better rates with respect to Southern ones [2].

Clinical cancer researchers and oncologists recognize the importance of measuring survival and the clinical effects of treatments as well as patients' quality of life in terms of subjective perceptions of symptoms, including physical, emotional and social functions [3, 4]. The increasing numbers of men with prostate cancer diagnoses and rising life expectancies underscore the importance of evaluating the quality of life of these patients [5, 6]. A number of studies have demonstrated that prostate cancer and its treatments affect physical and psychological health, as well as urinary, bowel and sexual function, with effects that seem to differ depending on the stage of the disease and the treatment being given [5, 7].

The National Research Council (CNR) prostate cancer monitoring project in Italy (Pros-IT CNR) is an ongoing study that is monitoring a sample population of Italian patients who were enrolled at the time they were diagnosed as new cases of prostate cancer. It aims to analyze the quality of life and general psychological and physical health parameters in real-world treatment situations during a 60 month study period. The current article reports on the health and quality of life registered at the study's baseline when the patients were newly diagnosed with prostate cancer.

\section{Methods}

\section{Study design}

The Pros-IT CNR study design has been described elsewhere [8]. Briefly, the Pros-IT CNR is a multicenter, prospective study that aims to monitor the quality of life of a sample of Italian male patients 18 years and older who were diagnosed with biopsy-verified treatment-naïve prostate cancer after September 1, 2014.

Ninety-seven centers including 51 Urology, 39 Radiation Oncology and 7 Oncological facilities located throughout Italy were actively involved in the enrollment phase. The baseline questionnaires were administered at the time prostate cancer was diagnosed. Six follow-up evaluations $6,12,24,36,48$ and 60 months after the original diagnostic assessment were scheduled for the patients.

\section{Ethics}

The Pros-IT CNR study protocol was approved by the Ethics Committee of the clinical coordinating center located at the Sant'Anna Hospital (Como, Italy; register number 45/2014). It was also approved by the Ethics Committees of each of the other participating centers. The study was carried out in accordance with the principles of the Declaration of Helsinki; all the participants gave informed consent.

\section{Outcomes measures}

Patients' quality of life was evaluated using the validated Italian version of the University of California Los Angeles-Prostate Cancer Index (Italian UCLA-PCI; [9]) and the validated version of the Short Form Health Survey (SF-12 Standard v1 scale; [10]). Both questionnaires were recommended for use in men with prostate cancer by the authors of a recent systematic review [11]. The UCLA-PCI which received high ratings for its psychometric properties (content validity, internal consistency, construct validity and reproducibility), was recommended to evaluate health-related quality of life in prostate cancer patients. UCLA-PCI specifically evaluates urinary function and bother (UF, UB), bowel function and bother (BF, BB), and sexual function and bother (SF, SB). Scores range from 0 to 100 , with higher score indicating better conditions.

SF-12 received high ratings for its criterion validity, construct validity, reproducibility, and interpretability; it was also recommended in view of its shortness [11]. The patients' Physical and mental quality of life (Physical Component Summary (PCS) and Mental Component Summary (MCS), respectively) were evaluated using the SF-12 and possible scores range from 0 to 100 , with 100 indicating best self-perceived health. Patients, who were originally evaluated at the time of diagnosis/enrollment, and are re-assessed at each of the appointments scheduled over the 60-month study period.

\section{Data collection}

The participating centers identified eligible patients who were newly diagnosed with prostate cancer. After signing the informed consent form, a baseline Data Collection Form (DCF) was completed by the referring specialist using a web-platform that was specifically created for the study. The Italian version of the UCLA-PCI questionnaire was, instead, printed and completed by each patient privately, and then returned to the specialist who loaded the responses into the web-platform.

\section{Statistical analysis}

The missing baseline data were analyzed without imputation of missing data.

Categorical variables are presented as numbers and percentages. Continuous variables are reported as means and standard deviations (SD) or medians and interquartile ranges for skewed variables. Normal distributions of continuous variables were tested using the Shapiro-Wilk test. 
Table 1 Socio-demographic characteristics and anamnestic data of the participants of the Pros-IT CNR study at the time they were diagnosed with prostate cancer

\begin{tabular}{|c|c|}
\hline & $n=1705$ \\
\hline \multicolumn{2}{|l|}{ Socio-demographic characteristics at diagnosis } \\
\hline \multicolumn{2}{|l|}{ Age at diagnosis, years } \\
\hline mean $\pm \mathrm{SD}$ & $68.9 \pm 7.4$ \\
\hline $\min , \max$ & 43,86 \\
\hline \multicolumn{2}{|l|}{ Education, n (\%) } \\
\hline University degree & $103(12.0)$ \\
\hline High school diploma & $596(35.6)$ \\
\hline Lower secondary school diploma & $393(23.5)$ \\
\hline Elementary license or less & $485(28.9)$ \\
\hline \multicolumn{2}{|l|}{ Marital status, n (\%) } \\
\hline Married or cohabiting & $1442(84.9)$ \\
\hline Widowed & $98(5.8)$ \\
\hline Separated, divorced or single & $159(9.4)$ \\
\hline \multicolumn{2}{|l|}{ Living arrangements, n (\%) } \\
\hline With spouse and/or children & $1535(90.3)$ \\
\hline Alone & $165(9.7)$ \\
\hline \multicolumn{2}{|l|}{ Work condition, n (\%) } \\
\hline Retired & $1263(74.7)$ \\
\hline Still working & $398(23.6)$ \\
\hline Unemployed & $29(1.7)$ \\
\hline \multicolumn{2}{|l|}{ Anamnestic data at diagnosis } \\
\hline \multicolumn{2}{|l|}{ BMI, n (\%) } \\
\hline Under/normal weight $\left(<25 \mathrm{~kg} / \mathrm{m}^{2}\right)$ & $568(34.2)$ \\
\hline Overweight $(25-29.9$ kg/m²) & $832(50.1)$ \\
\hline Obesity $\left(\geq 30 \mathrm{~kg} / \mathrm{m}^{2}\right)$ & $260(15.7)$ \\
\hline \multicolumn{2}{|l|}{ Smoking status, n (\%) } \\
\hline Current smoker & $230(13.8)$ \\
\hline Former smoker & $688(41.3)$ \\
\hline Never smoker & $747(44.9)$ \\
\hline Family history of prostate cancer, n (\%) & $286(17.0)$ \\
\hline Family history of breast cancer, $\mathrm{n}(\%)$ & $80(5.8)$ \\
\hline Family history of ovarian cancer, n (\%) & $25(2.1)$ \\
\hline Diabetes mellitus, n (\%) & $263(15.5)$ \\
\hline \multicolumn{2}{|c|}{$\begin{array}{l}\text { Patients reporting moderate, severe or extremely severe impairment } \\
\text { for individual CIRS items, } \mathrm{n}(\%)\end{array}$} \\
\hline Cardiac & $322(19.0)$ \\
\hline Hypertension & $17(1.0)$ \\
\hline Vascular, haematological & $464(27.3)$ \\
\hline Respiratory & $61(3.6)$ \\
\hline Eye, ear, nose and throat & $146(8.6)$ \\
\hline Upper gastrointestinal & $236(13.9)$ \\
\hline Lower gastrointestinal & $88(5.2)$ \\
\hline Hepatic & $110(6.5)$ \\
\hline
\end{tabular}

Table 1 Socio-demographic characteristics and anamnestic data of the participants of the Pros-IT CNR study at the time they were diagnosed with prostate cancer (Continued)

\begin{tabular}{ll}
\hline & $n=1705$ \\
\hline Renal & $86(5.1)$ \\
Other genitourinary & $51(3.0)$ \\
Musculoskeletal, integumentary & $82(3.0)$ \\
Neurological, excluding dementia & $174(10.4)$ \\
Endocrine, metabolic & $83(4.9)$ \\
Psychiatric, behavioural & $31(1.8)$ \\
\hline
\end{tabular}

SD Standard Deviation, CIRS Cumulative Illness Rating Scale

The patients' overall quality of life, assessed using the SF-12 (PCS and MCS), and their quality of life linked to urinary, bowel and sexual function, assessed using the Italian version of the UCLA-PCI, were analyzed in relation to demographic characteristics, risk factors and disease-staging using a Generalized Linear Model (GLM) on rank-transformed data, adjusting for age at diagnosis.

Multivariable logistic regression models were defined, with outcomes the PCS and MCS SF-12 scores as well as the urinary, bowel and sexual functions of the UCLA-PCI, dichotomized according to the first quartile of their distribution (Q1). Each model was adjusted for age at diagnosis (years), education (lower secondary school diploma or less vs high school diploma or University degree), marital status (married or cohabitating vs widowed, divorced or single), geographical area of residence (northern regions of Italy vs central or southern regions), Body Mass Index (BMI; normal weight vs overweight or obesity), smoking status (current smoker vs former or never), diabetes mellitus, having three or more moderate/severe comorbidities, $\mathrm{T}$ stage (T1 vs T2 or T3-T4) and Gleason score at diagnosis $(6$ vs $3+4,4+3,8+)$.

All statistical tests were two-tailed, and $p$-values $<0.05$ were considered statistically significant. All the analyses were performed using the SAS 9.4 statistical software.

\section{Results}

One thousand seven hundred fifty-three patientswith a biopsy-verified prostate cancer were originally enrolled. Forty-eight protocol violations were registered in relation to inclusion criteria: diagnoses were formulated before September 1, 2014 for 35 patients and 13 were not naïve to prostate cancer treatments. Excluding those patients, our sample was made up of 1705 patients: 949 (55.7\%) were enrolled in Urology, 717 (42.1\%) in Radiation Oncology and $39(2.3 \%)$ in Oncological Departments.

More than half of the participants were residing at the time of diagnosis in Northern Italy, about a quarter in Central Italy and the rest in Southern regions of the country. A "health migration" phenomenon was noted in these patients, as many travelled to centers located in 
the North to undergo diagnosis and/or treatment. In fact, 13.7 and $9 \%$ of patients residing in the South and Central areas, respectively, were enrolled at centers located in the North.

\section{Socio-demographic characteristics}

The main socio-demographic data are presented in Table 1. The patients' mean age at diagnosis was $68.9 \pm$ 7.4 years. Almost $12 \%$ of the participants had a university degree, 36\% had a high school diploma, and almost 30\% had completed elementary school or had no study degree. Eighty-five percent of the participants were married or cohabiting. More than $90 \%$ of the participants were living with other members of their family such as a spouse and/ or children. Approximately three-quarters were retired.

\section{Anamnestic data}

More than half of the patients were overweight and had a BMI between 25 and $29.9 \mathrm{~kg} / \mathrm{m}^{2}$ (Table 1). Almost
$14 \%$ declared that they were current smokers, while $41 \%$ were former smokers.

Seventeen percent of the patients reported having a family history of prostate cancer; 5.8 and $2.1 \%$, respectively, reported family breast and ovarian cancer history. The mean age at the diagnosis of prostate cancer in the participants with a family history of the disease was significantly lower than that in those without one $(66.8 \pm 8.3$ vs $69.3 \pm 7.2, p<0.0001)$.

Two hundred sixty three patients (15.5\%) declared that they had diabetes mellitus. Four hundred sixty-four of the patients (27.3\%) reported having moderate, severe or extremely severe diseases, as defined by the Cumulative Illness Rating Scale (CIRS; [12]), of the vascular, lymphatic or hematopoietic system; 322 (19.0\%) referred having a disease of the cardiac system, 236 (13.9\%) of the gastrointestinal apparatus and $174(10.3 \%)$ of the neurological system, excluding dementia.
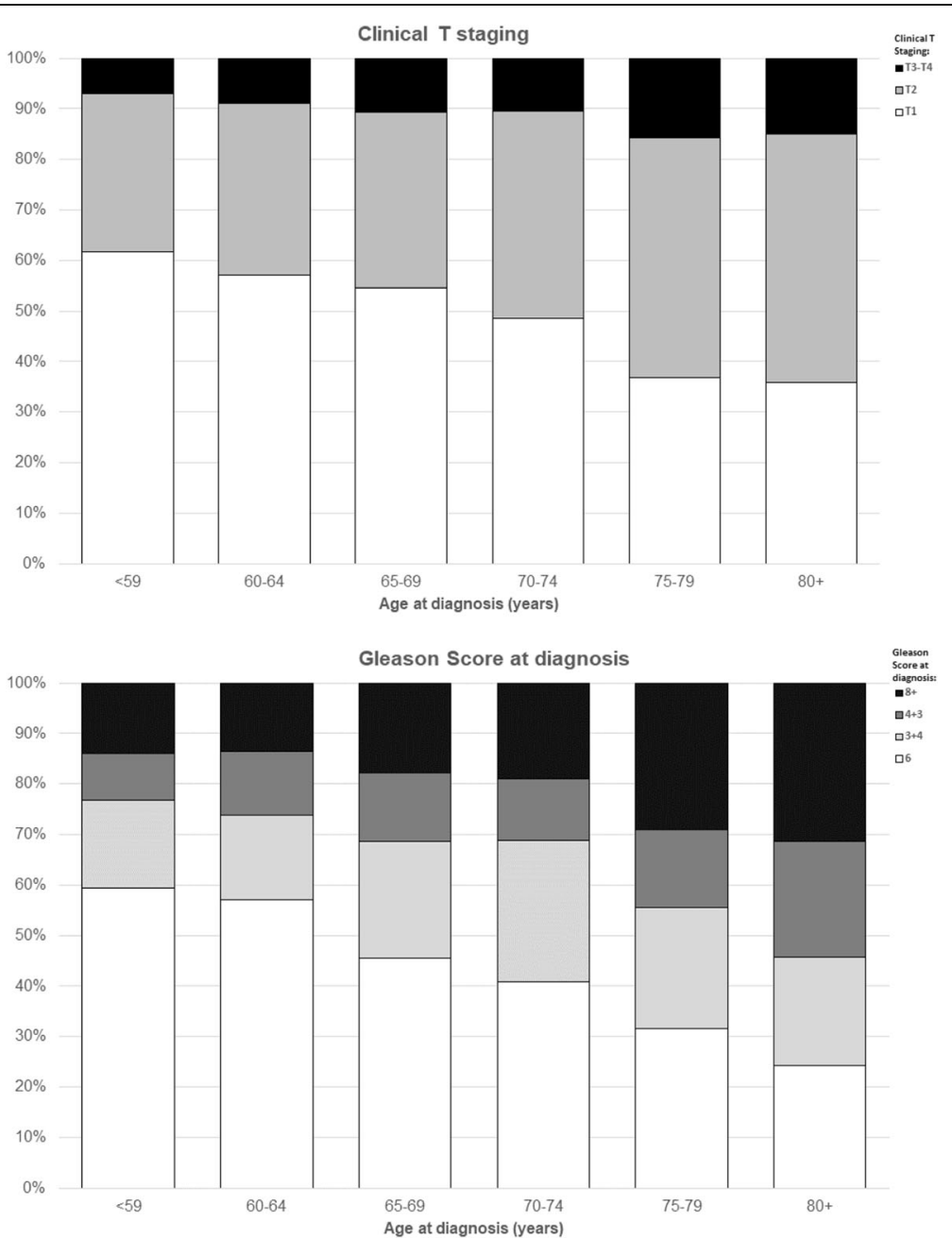

Fig. 1 Clinical T staging (a) and Gleason score (b) of the participants of the Pros-IT CNR study by age classes at diagnosis 
Table 2 Demographic data and responses to the physical (PCS) and mental components (MCS) of the SF-12 of the participants of the Pros-IT CNR study at the time they were diagnosed with prostate cancer

\begin{tabular}{|c|c|c|c|c|}
\hline & PCS* & $p$-value & $\mathrm{MCS}^{*}$ & $p$-value \\
\hline $\begin{array}{l}\text { Age at diagnosis } \\
\text { (years) }\end{array}$ & & $<0.0001^{\S}$ & & $0.0058^{\mathrm{s}}$ \\
\hline$<60$ & $54.4 \pm 6.2$ & & $47.3 \pm 9.9$ & \\
\hline $60-64$ & $52.8 \pm 6.6$ & & $48.5 \pm 9.7$ & \\
\hline $65-69$ & $52.2 \pm 6.8$ & & $50.2 \pm 9.3$ & \\
\hline $70-74$ & $51.1 \pm 7.7$ & & $49.5 \pm 10.1$ & \\
\hline $75-79$ & $50.1 \pm 8.0$ & & $49.9 \pm 9.3$ & \\
\hline $80+$ & $48.1 \pm 10.2$ & & $49.9 \pm 9.0$ & \\
\hline Education & & 0.4460 & & 0.5036 \\
\hline University degree & $52.7 \pm 6.6$ & & $49.6 \pm 9.4$ & \\
\hline $\begin{array}{l}\text { High school } \\
\text { diploma }\end{array}$ & $52.1 \pm 7.2$ & & $49.0 \pm 9.5$ & \\
\hline $\begin{array}{l}\text { Lower secondary } \\
\text { school diploma }\end{array}$ & $51.2 \pm 7.9$ & & $49.0 \pm 9.8$ & \\
\hline $\begin{array}{l}\text { Elementary license } \\
\text { or less }\end{array}$ & $51.0 \pm 7.9$ & & $50.0 \pm 9.8$ & \\
\hline Marital status & & 0.5575 & & 0.4830 \\
\hline $\begin{array}{l}\text { Married or } \\
\text { cohabiting }\end{array}$ & $51.8 \pm 7.4$ & & $49.5 \pm 9.4$ & \\
\hline Widowed & $51.1 \pm 7.7$ & & $49.1 \pm 10.2$ & \\
\hline $\begin{array}{l}\text { Separated, divorced } \\
\text { or single }\end{array}$ & $51.1 \pm 8.0$ & & $48.0 \pm 11.0$ & \\
\hline $\begin{array}{l}\text { Geographical area } \\
\text { of residence }\end{array}$ & & 0.0002 & & 0.0991 \\
\hline North Italy & $51.7 \pm 7.5^{\mathrm{a}}$ & & $49.9 \pm 9.6$ & \\
\hline Central Italy & $52.3 \pm 7.2^{b}$ & & $49.0 \pm 9.7$ & \\
\hline Southern Italy & $50.4 \pm 7.8^{\mathrm{ab}}$ & & $48.7 \pm 9.8$ & \\
\hline BMl & & $<0.0001$ & & 0.3796 \\
\hline $\begin{array}{l}\text { Under/normal } \\
\text { weight }\left(<25 \mathrm{~kg} / \mathrm{m}^{2}\right)\end{array}$ & $52.0 \pm 7.5^{a}$ & & $49.1 \pm 9.7$ & \\
\hline $\begin{array}{l}\text { Overweight } \\
\left(25-29.9 \mathrm{~kg} / \mathrm{m}^{2}\right)\end{array}$ & $52.0 \pm 7.1^{b}$ & & $49.5 \pm 9.5$ & \\
\hline Obesity $\left(\geq 30 \mathrm{~kg} / \mathrm{m}^{2}\right)$ & $49.7 \pm 8.4^{\mathrm{ab}}$ & & $49.7 \pm 9.9$ & \\
\hline Smoking status & & 0.1576 & & 0.4419 \\
\hline $\begin{array}{l}\text { Non-smoker } \\
\text { or former }\end{array}$ & $51.6 \pm 7.6$ & & $49.4 \pm 9.6$ & \\
\hline Current smoker & $51.9 \pm 7.2$ & & $48.4 \pm 10.1$ & \\
\hline Diabetes mellitus & & $<0.0001$ & & 0.1894 \\
\hline No & $52.0 \pm 7.3$ & & $49.4 \pm 9.7$ & \\
\hline Yes & $49.6 \pm 8.4$ & & $49.0 \pm 9.6$ & \\
\hline $\begin{array}{l}\text { Number of moderate/ } \\
\text { severe comorbidities } \\
\text { (according to CIRS) }\end{array}$ & & $<0.0001$ & & $<0.0001$ \\
\hline $0-2$ & $52.5 \pm 6.7$ & & $49.8 \pm 9.4$ & \\
\hline $3+$ & $47.0 \pm 9.9$ & & $46.8 \pm 10.4$ & \\
\hline
\end{tabular}

Table 2 Demographic data and responses to the physical (PCS) and mental components (MCS) of the SF-12 of the participants of the Pros-IT CNR study at the time they were diagnosed with prostate cancer (Continued)

\begin{tabular}{lllll}
\hline & PCS $^{*}$ & p-value & MCS* $^{*}$ & p-value \\
\hline T staging at diagnosis & & 0.8226 & & $<0.0001$ \\
T1 & $52.0 \pm 7.2$ & & $50.4 \pm 9.3^{\text {ab }}$ & \\
T2 & $51.6 \pm 7.6$ & & $48.7 \pm 9.6^{\mathrm{a}}$ & \\
T3 or T4 & $51.1 \pm 7.9$ & & $48.6 \pm 10.1^{\mathrm{b}}$ & \\
Gleason score & & 0.3409 & & 0.1599 \\
at diagnosis & & & & \\
6 & $52.1 \pm 7.0$ & & $49.6 \pm 9.3$ & \\
$3+4$ & $51.9 \pm 7.3$ & & $50.0 \pm 9.5$ & \\
$4+3$ & $51.6 \pm 7.8$ & & $48.6 \pm 10.3$ & \\
$8+$ & $50.7 \pm 8.3$ & & $48.7 \pm 10.1$ & \\
\hline
\end{tabular}

*mean \pm SD

${ }^{\S} \mathrm{p}$-value from test for trend

a, bsignificant post-hoc ( $p<0.05$ adjusting for age at diagnosis)

At enrollment, more than $70 \%$ of the participants were taking at least one medication; the median number of drugs assumed was three (interquartile range IQ 1-4). Precisely $53.7 \%$ were taking drugs for the circulatory system, $27 \%$ of the participants were receiving antithrombotic agents, $25.4 \%$ were medication for the digestive system and metabolism (16.4\% for acidosis, $10.6 \%$ hypoglycemic drugs). About one quarter of the enrolled patients $(22.6 \%)$ were taking urological drugs for lower urinary tract symptoms or for erectile dysfunction.

\section{Diagnosis}

The median prostate-specific antigen (PSA) level at diagnosis was $7.2 \mathrm{ng} / \mathrm{mL}$ (IQ 5.2-10.6). Approximately half of the study participants had a T1 clinical stage (786, $48 \%), 38.6$ and $11.4 \%$ had a T2 or T3-T4clinical stage, respectively. The Gleason score for prostate biopsy tissue was six for 718 patients (42.8\%), $3+4$ for 381 (22.7\%), $4+3$ for 233 (13.9\%) and $8+$ for 349 patients (20.8\%). The association of age at diagnosis with both the clinical T stage and the Gleason score was significant $(p<0.0001$ for trend; Fig. 1a, b).

\section{Quality of life: SF-12}

Complete responses to the SF-12 were available for 1664 participants (data was missing for $2.4 \%$ of the participants). The mean PCS value for the entire study population was $51.6 \pm 7.5$; the mean MCS value was $49.3 \pm 9.7$. While mean PCS scores tended to be lower in the oldest patients $(p<0.0001)$, the mean MCS scores tended to be higher in the oldest patients $(p=0.0059)$.

Table 2 outlines the mean PCS and MCS values at diagnosis analyzed together with other characteristics of 
the participants. The characteristics associated with lower PCS scores in the multivariable logistic regression model were age (Odds Ratio OR 1.06 for each year of age, 95\% Confidence Interval CI 1.04-1.08, $p<0.0001$ ), obesity (OR 1.84, 95\% CI 1.27-2.65, $p=0.0012$ ), the presence of three or more moderate/severe comorbidities (OR 2.75, 95\% CI 2.01-3.76, p < 0.0001) and a Gleason score at diagnosis of $8+(\mathrm{OR}=1.44,95 \% \mathrm{CI}$ $1.02-2.05, p=0.0401)$. Living in Southern regions of Italy and being widowed or single were also associated with lower PCS scores in the multivariable model $(\mathrm{OR}=1.69$, 95\% CI 1.23-2.33, $p=0.0013$ and $\mathrm{OR}=1.42,95 \% \mathrm{CI}$ $1.02-1.98, \mathrm{p}=0.040$, respectively).

The characteristics associated with lower MCS scores in the multivariable logistic model were younger age $(\mathrm{OR}=0.97,95 \%$ CI $0.96-0.98, \mathrm{p}=0.0012)$, the presence of three or more moderate/severe comorbidities (OR 1.95 , 95\% CI $1.42-2.70, p<0.0001)$, a T-score at diagnosis that was higher than T1 (T2 vs T1 OR 1.51, 95\% CI $1.15-1.98, p=0.0029$; T3-T4 vs T1 OR $1.62,95 \%$ CI $1.06-2.48, p=0.0253)$.

\section{Quality of life: UCLA-PCI}

Complete responses to the UCLA-PCI were available for 1645 participants (3.5\% missing data). At the time prostate cancer was diagnosed, urinary function was good $(93.2 \pm 15.7)$ and urinary bother scores were low $(88.5 \pm 23.3)$. Four point $9 \%$ of the study participants reported using at least one safety pad daily to control urinary loss; the increase with age was not significant $(p=0.1943)$ : the percent ranged from $3.2 \%$ in the patients younger than 65 to $5.8,5.3$ and $5.4 \%$ in the patients between 65 and 69, 70-74 and 75-older, respectively. The use of a daily safety pad to control urinary loss was significantly associated with lower urinary bother scores $(45.7 \pm 29.3$ vs $90.7 \pm 20.7, \mathrm{p}<0.0001)$.

Bowel function and bother scores on the UCLA-PCI were generally good $(93.6 \pm 13.2$ and $93.3 \pm 18.3$, respectively), and less than $3 \%$ of the participants reported a moderate or severe problem attributable to bowel function. The mean sexual function and bother scores were $48.6 \pm 32.2$ and $64.1 \pm 35.0$, respectively. Twenty-six point $7 \%$ of the participants declared that their sexual function was a moderate/large problem: the percentages ranged from 22.9 to $23.8 \%$ to 29.8 and $30.5 \%$ in the patients younger than 65 , between 65 and $69,70-74$ or 75 or older respectively $(p=0.0044)$.

Age was the main characteristic associated with prostate cancer scores (Fig. 2; Table 3), also in the multivariable logistic regression models; the $p$-values for trend with increasing age were statistically significant for every health aspect evaluated by UCLA-PCI.

Variables significantly associated with lower scores on sexual function in the multivariable models were age (OR 1.10, 95\% CI 1.08-1.13, $p<0.0001)$, diabetes $(\mathrm{OR}=1.40$, $95 \%$ CI 1.01-1.96, $p=0.0485)$, three or more moderate/severe comorbidities according to CIRS (OR 1.55, 95\% CI 1.11-2.16, $p=0.0103)$, T2 or T3-T4 at diagnosis $(\mathrm{OR}=1.42,95 \% \mathrm{CI} 1.06-1.89, p=0.0185$, and $\mathrm{OR}=1.75$, 95\% CI 1.14-2.69, $p=0.0093$, vs T1, respectively) and a Gleason score of eight or more $(\mathrm{OR}=2.03,95 \% \mathrm{CI}$ $1.42-2.92, p=0.0001$ ).

\section{Discussion}

The PROS-IT CNR Study allows to assess the quality of life of males diagnosed as new cases of prostate cancer in Italy. More than half of the patients reside in Northern Italy, a fact that is linked to the geography of the centers, which all voluntarily agreed to participate in

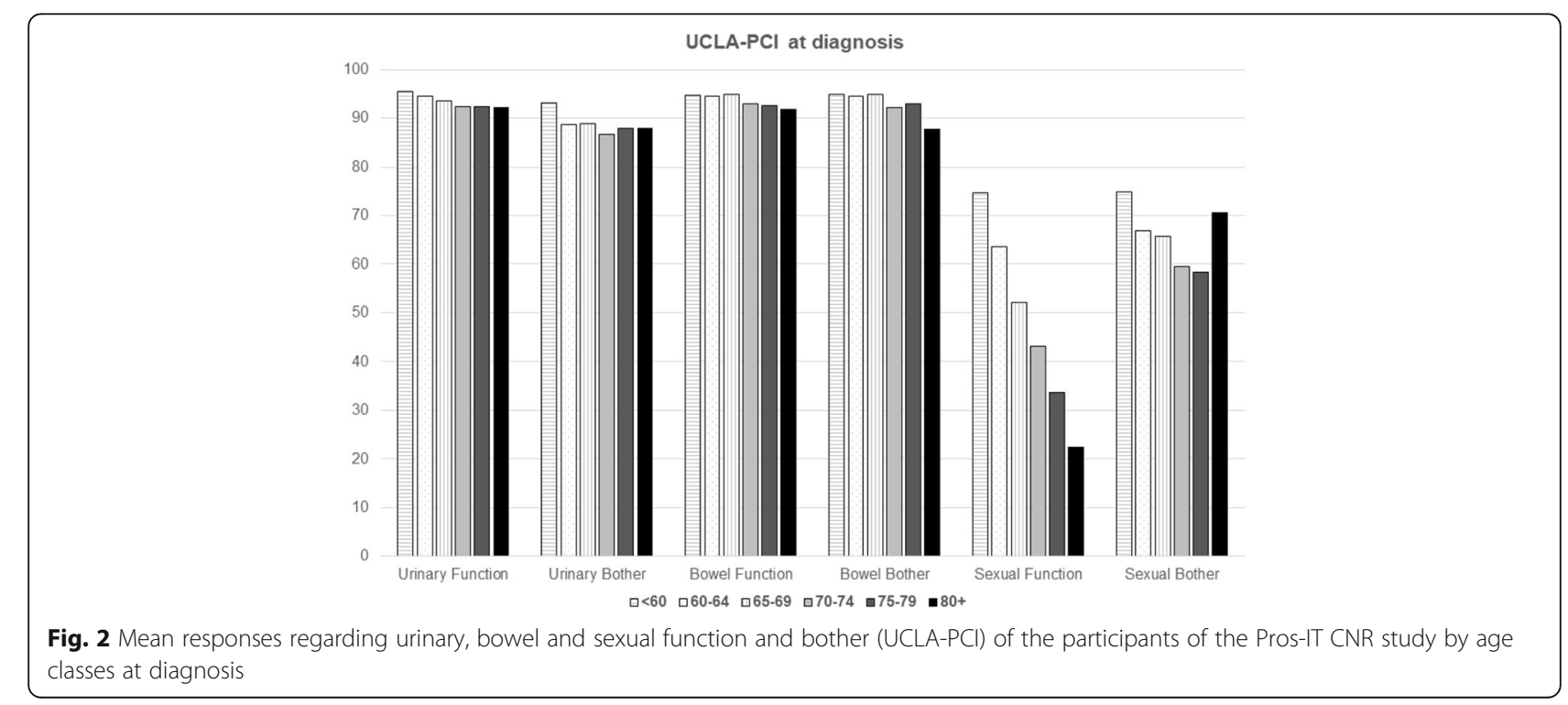




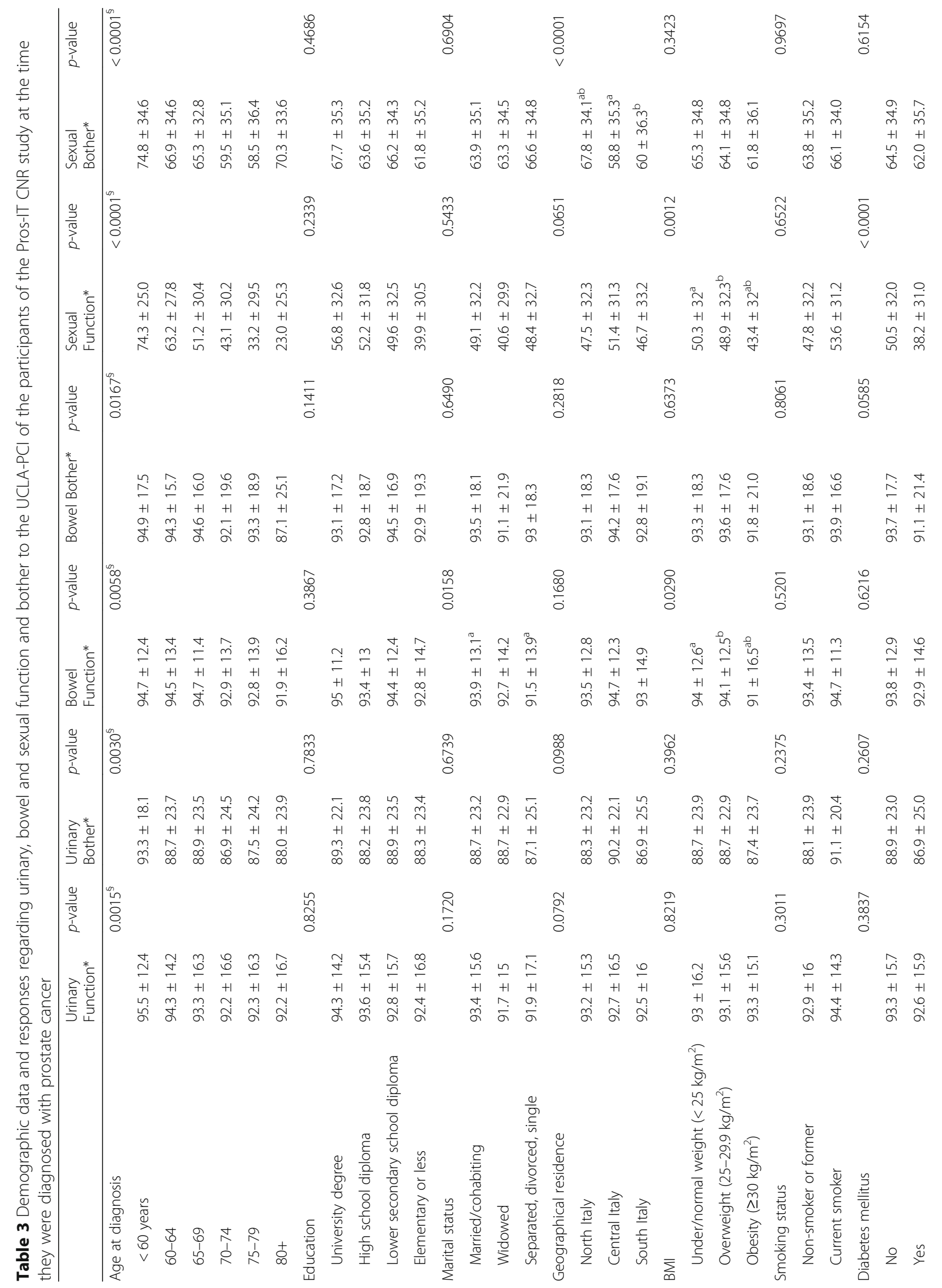




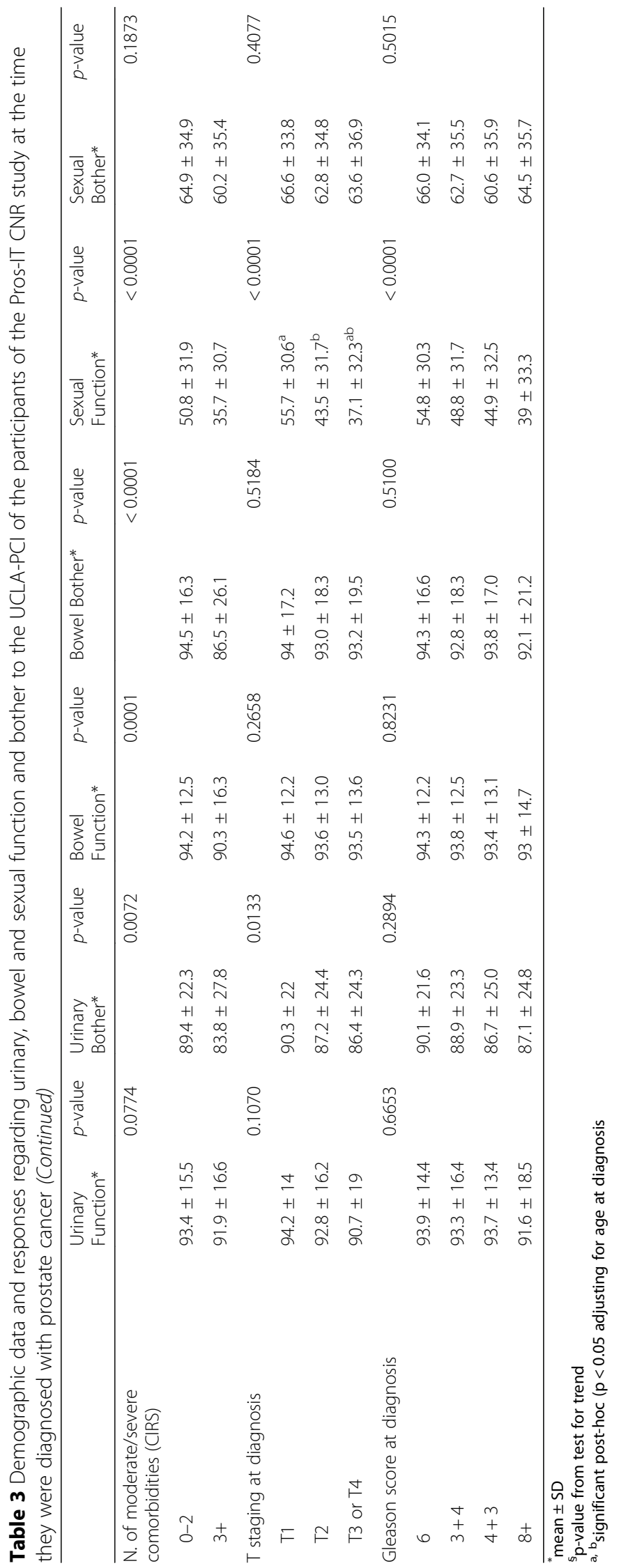


the study. Half, in fact, are located in the North; approximately a fourth are located in Central Italy and the rest in the Southern part of the country. According to the last report of the Italian Association of Cancer Registry (AIRTUM), the standardized incidence of prostate cancer was inferior in the Southern and Central regions with respect to that in the Northern ones (68 and 85.7 vs 99.8 per 100,000 men) [2]. Official records also show that while the Southern part of Italy is characterized by a lower incidence rate of prostate cancer, it nonetheless also registers a shorter survival rate. Our study will provide evidence on potential delay in the diagnosis of prostate cancer in South Italy, which could explain these epidemiological trends.

The patients participating in the Pros-IT CNR study were found to be characterized by a higher education with respect to data referring to the general population of males over 75 reported by the Italian Statistics Institute (ISTAT) [13]. While $12 \%$ of the men enrolled in our study had a university degree, only $7 \%$ of the general population did so. While $30 \%$ of the participants completed grade school or had no official schooling, 48.6\% of the general male elderly population did so. The differences in educational status of the participants and the general population, seem to suggest that socio-economic characteristics might be associated to the risk of prostate cancer in the Italian population. We cannot however exclude a selection bias as more highly educated males may have agreed to participate in the study.

The mean score physical SF-12 component score was 51.7, which was higher than that described by the ISTAT in males between 65 and 74 (48.4) or those over 75 (41.5). The scores on the emotional-psychological SF-12 component in the participants were consistent with those reported by the ISTAT in males between 65 and 74 and slightly higher than those calculated for men over 75 [13]. These results disagree to some extent with what has been reported by other studies. For example, both the investigators of the ProtecT trial and a review on prostate cancer and health-related quality of life, reported scores on the two SF-12 components in just diagnosed patients that were consistent with those in the population at large $[5,7]$. Moreover, according to other studies, just diagnosed with prostate cancer patients had lower scores on the emotional-psychological component with the respect to those in the general population [14, 15]. Again, these results could be explained by the higher level of education of the participants in our sample compared to that of the general population, a factor that is usually associated to an overall better physical and emotional health.

The scores on the physical component and thus concerning the perception of physical health were worse, in our study, in the older age-groups, while those concerning emotional-psychological status tended to be worse in the youngest age-group, suggesting, just as has been point out in other studies, that a certain amount of psyco-emotional adjustment takes place with aging $[16,17]$.

It is interesting that worse emotional-psychological component scores were associated to worse $\mathrm{T}$ classes at diagnosis regardless of age or other confounding factors such as comorbidities. Likewise, worse $\mathrm{T}$ or Gleason scores at diagnosis were associated to worse scores on sexual function, although in some studies men with localized prostate cancer reported more sexual problems with respect to same-age peers without cancer [3].

Approximately $5 \%$ of the patients included in our study declared that they used at least one safety pad daily to control urinary loss. That percentage did not change in the older patients, but it did when there were other urinary disturbances. This baseline finding is of primary relevance when post-treatment continence is being defined and evaluated.

The Pros-IT CNR study has several strengths, including its multidisciplinary approach and its prospective design. The study's longitudinal design that foresees monitoring the participants for 60 months from the time of diagnosis, will allow to evaluate the disease's evolution over time and the patients quality of life. One of the study's limitations instead is connected to the fact that centres were involved on a voluntary basis and a selection bias cannot be excluded.

\section{Conclusions}

The importance of the results presented here is twofold: they draw a profile of the general state of health and the subjective perception of quality of life of patients who have just been diagnosed with prostate cancer. Moreover, they underscore the patients' characteristics at diagnosis that are relevant for appreciating the variations over time of their quality of life. More detailed knowledge about patients' pre-treatment status and perception of health and quality of life will be essential to evaluate their response to treatment and to permit us to compare our data with those reported by other studies.

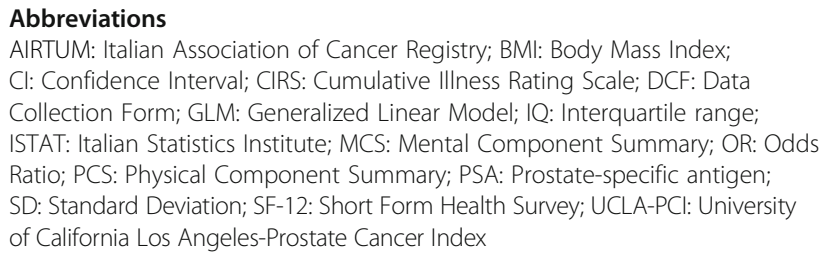

\section{Acknowledgements}

The authors wish to thank Linda Inverso Moretti for reviewing the English version of this paper.

The Pros-IT CNR Group:

Steering Committee: Crepaldi Gaetano (Padova); Maggi Stefania (Padova); Noale Marianna (Padova); Porreca Angelo (Padova); Artibani Walter (Verona); Bassi Pierfrancesco (Roma); Bracarda Sergio (Arezzo); Conti Giario Natale 
(Como); Corvò Renzo (Genova); Graziotti Pierpaolo (Milano); Russi Elvio (Cuneo); Mirone Vincenzo (Napoli); Montironi Rodolfo (Ancona).

Scientific Committee: Bertoni Filippo (Brescia); Gacci Mauro (Firenze); Magrini Stefano Maria (Brescia); Muto Giovanni (Roma); Pecoraro Stefano (Avellino); Ricardi Umberto (Torino); Tubaro Andrea (Roma); Zagonel Vittorina (Padova). Working Group: Alitto Anna Rita (Roma); Ambrosi Enrica (Brescia); Antonelli Alessandro (Brescia); Aristei Cynthia (Perugia); Barbieri Michele (Napoli); Bardari Franco (Asti); Bardoscia Lilia (Brescia); Barra Salvina (Genova); Bartoncini Sara (Torino); Basso Umberto (Padova); Becherini Carlotta (Firenze); Bellavita Rita (Perugia); Bergamaschi Franco (Reggio Emilia); Berlingheri Stefania (Brescia); Berruti Alfredo (Brescia); Borghesi Marco (Bologna); Bortolus Roberto (Pordenone); Borzillo Valentina (Napoli); Bosetti Davide (Milano); Bove Giuseppe (Foggia); Bove Pierluigi (Roma); Brausi Maurizio (Modena); Bruni Alessio (Modena); Bruno Giorgio (Ravenna); Brunocilla Eugenio (Bologna); Buffoli Alberto (Brescia); Buglione Michela (Brescia); Buttigliero Consuelo (Torino); Cacciamani Giovanni (Verona); Caldiroli Michela (Varese); Cardo Giuseppe (Bari); Carmignani Giorgio (Genova); Carrieri Giuseppe (Foggia); Castelli Emanuele (Torino); Castrezzati Elisabetta (Brescia); Catalano Gianpiero (Milano); Cattarino Susanna (Roma); Catucci Francesco (Roma); Cavallini Francolini Dario (Pavia); Ceccarini Ofelia (Bergamo); Celia Antonio (Vicenza); Chiancone Francesco (Napoli); Chini Tommaso (Firenze); Cianci Claudia (Pisa); Cisternino Antonio (Foggia); Collura Devis (Torino); Corbella Franco (Pavia); Corinti Matteo (Como); Corsi Paolo (Verona); Cortese Fiorenza (Alessandria); Corti Luigi (Padova); Cosimo de Nunzio (Roma); Cristiano Olga (Avellino); D'Angelillo Rolando M. (Roma); Da Pozzo Luigi (Bergamo); D'agostino Daniele (Padova); D'Elia Carolina (Bolzano): Dandrea Matteo (Padova); De Angelis Michele (Arezzo); De Angelis Paolo (Novara); De Cobelli Ottavio (Milano); De Concilio Bernardino (Vicenza); De Lisa Antonello (Cagliari); De Luca Stefano (Torino); De Stefani Agostina (Bergamo); Deantoni Chiara Lucrezia (Milano); Degli Esposti Claudio (Bologna); Destito Anna (Catanzaro); Detti Beatrice (Firenze); Di Muzio Nadia (Milano); Di Stasio Andrea (Alessandria); Di Stefano Calogero (Ravenna); Di Trapani Danilo (Palermo); Difino Giuseppe (Foggia); Falivene Sara (Napoli); Farullo Giuseppe (Roma); Fedelini Paolo (Napoli); Ferrari llaria (Varese); Ferrau Francesco (Messina); Ferro Matteo (Milano); Fodor Andrei (Milano); Fontanta Francesco (Novara); Francesca Francesco (Pisa); Francolini Giulio (Firenze); Frata Paolo (Brescia); Frezza Giovanni (Bologna); Gabriele Pietro (Torino); Galeandro Maria (Reggio Emilia); Garibaldi Elisabetta (Torino); Gennari Pietro Giovanni (Arezzo); Gentilucci Alessandro (Roma); Giacobbe Alessandro (Torino); Giussani Laura (Varese); Giusti Giuseppe (Cagliari); Gontero Paolo (Torino); Guarneri Alessia (Torino); Guida Cesare (Avellino); Gurioli Alberto (Torino); Huqi Dorijan (Bolzano); Imbimbo Ciro (Napoli); Ingrosso Gianluca (Roma); lotti Cinzia (Reggio Emilia); Italia Corrado (Bergamo); La Mattina Pierdaniele (Milano); Lamanna Enza (Ravenna); Lastrucci Luciana (Arezzo); Lazzari Grazia (Taranto); Liberale Fabiola (Biella); Liguori Giovanni (Trieste); Lisi Roberto (Roma); Lohr Frank (Modena); Lombardo Riccardo (Roma); Lovisolo Jon AJ (Varese); Ludovico Giuseppe Mario (Bari); Macchione Nicola (Novara); Maggio Francesca (Imperia); Malizia Michele (Bologna); Manasse Gianluca (Perugia); Mandoliti Giovanni (Rovigo); Mantini Giovanna (Roma); Marafioti Luigi (Cosenza); Marciello Luisa (Prato); Marconi Alberto Mario (Varese); Martilotta Antonietta (Cosenza); Marzano Salvino (Prato); Masciullo Stefano (Bergamo); Maso Gloria (Verbania); Massenzo Adele (Cosenza); Mazzeo Ercole (Modena); Mearini Luigi (Perugia); Medoro Serena (Ferrara): Molè Rosa (Catanzaro): Monesi Giorgio (Novara); Montanari Emanuele (Milano); Montefiore Franco (Alessandria); Montesi Giampaolo (Rovigo); Morgia Giuseppe (Catania); Moro Gregorio (Biella); Muscas Giorgio (Cagliari); Musio Daniela (Roma); Muto Paolo (Napoli); Muzzonigro Giovanni (Ancona); Napodano Giorgio (Salerno); Negro Carlo Luigi Augusto (Asti); Nidini Mattia (Mantova); Ntreta Maria (Bologna); Orsatti Marco (Imperia); Palazzolo Carmela (Messina); Palumbo Isabella (Perugia); Parisi Alessandro (Bologna); Parma Paolo (Mantova); Pavan Nicola (Trieste); Pericolini Martina (Roma); Pinto Francesco (Roma); Pistone Antonio (Salerno); Pizzuti Valerio (Grosseto); Platania Angelo (Messina); Polli Caterina (Prato); Pomara Giorgio (Pisa); Ponti Elisabetta (Roma); Porcaro Antonio Benito (Verona); Porpiglia Francesco (Torino); Pugliese Dario (Roma); Pycha Armin (Bolzano); Raguso Giuseppe (Reggio Emilia); Rampini Andrea (Arezzo); Randone Donato Franco (Torino); Roboldi Valentina (Bergamo); Roscigno Marco (Bergamo); Ruggieri Maria Paola (Reggio Emilia); Ruoppo Giuseppe (Reggio Emilia); Sanseverino Roberto (Salerno); Santacaterina Anna (Messina); Santarsieri Michele (Pisa); Santoni Riccardo (Roma); Scagliarini Sarah (Napoli); Scagliotti Giorgio Vittorio (Torino); Scanzi Mauro (Brescia); Scarcia Marcello (Bari); Schiavina Riccardo (Bologna); Sciarra Alessandro (Roma): Sciorio Carmine (Lecco): Scolaro Tindaro (La Spezia); Scuzzarella Salvatore (Lecco); Selvaggio Oscar (Foggia); Serao Armando (Alessandria);
Serni Sergio (Firenze); Signor Marco Andrea (Udine); Silvani Mauro (Biella); Silvano Giovanni (Taranto); Silvestris Franco (Bari); Simeone Claudio (Brescia); Simone Valeria (Bari); Spagnoletti Girolamo (Foggia); Spinelli Matteo Giulio (Milano); Squillace Luigi (Pavia); Tombolini Vincenzo (Roma); Toninelli Mariastella (Brescia); Triggiani Luca (Brescia); Trinchieri Alberto (Lecco); Trodella Luca Eolo (Roma); Trodella Lucio (Roma); Trombetta Carlo (Trieste); Tronnolone Lidia (Roma); Tucci Marcello (Torino); Urzi Daniele (Catania); Valdagni Riccardo (Milano); Valeriani Maurizio (Roma); Vanoli Maurizio (La Spezia); Vitali Elisabetta (Bergamo); Volpe Alessandro (Novara); Zaramella Stefano (Novara); Zeccolini Guglielmo (Vicenza); Zini Giampaolo (Ferrara).

\section{Funding}

Pros-IT CNR is a non-profit observational study. Takeda Italia S.p.A. has been furnishing CNR with a non-conditional grant to cover the cost of developing a web platform for data entry and the travel expenses of the Steering Committee, the Working Group, and the Scientific Committee.

\section{Availability of data and materials}

The Pros-IT CNR participating data are available only to the collaborating scientists within the study.

\section{Authors' contributions}

All authors participated in the study design; SM, MN and AP drafted the manuscript. All the authors critically reviewed and approved the final manuscript.

\section{Ethics approval and consent to participate}

The Pros-IT CNR study protocol was approved by the Ethics Committee of the clinical coordinating center located at the Sant'Anna Hospital (Como, Italy; register number 45/2014). It was also approved by the Ethics Committees of each of the other participating centers.

All participants gave informed consent.

\section{Competing interests}

AP, MN, WA, PFB, FB, GNC, RC, MG, SMM, VM, RM, GM, SP, UR, VZ declare that they have no conflicts of interest. AT reports personal fees and other from Astellas, other from Allergan, other from Bayer, other from GSK, personal fees and other from Pierre Fabre, other from Takeda, outside the submitted work. SM and GC report grants from Takeda, during the conduct of the study; personal fees from Takeda, outside the submitted work. Conflict of interest forms for $P G, E R$ and $S B$ were not received.

\section{Publisher's Note}

Springer Nature remains neutral with regard to jurisdictional claims in published maps and institutional affiliations.

\section{Author details}

${ }^{1}$ Policlinico di Abano Terme, Padova, Italy. ${ }^{2}$ National Research Council (CNR), Neuroscience Institute, Aging Branch, Via Giustiniani 2, 35128 Padova, Italy. ${ }^{3}$ Azienda Ospedaliera Universitaria Integrata di Verona, Verona, Italy. ${ }^{4}$ Policlinico Universitario A. Gemelli, Università Cattolica del Sacro Cuore di Milano - Sede di Roma, Roma, Italy. ${ }^{5}$ Prostate Group of AIRO - Italian Association for Radiation Oncology, Milano, Italy. ${ }^{6}$ Ospedale San Donato, Arezzo, Italy. ${ }^{7}$ Ospedale Sant'Anna, Como, Italy. ${ }^{8}$ IRCCS San Martino-IST, Genova, Italy. ${ }^{9}$ Università di Firenze, Firenze, Italy. ${ }^{10}$ Ospedale S. Giuseppe, Milano, Italy. ${ }^{11}$ Università di Brescia, Brescia, Italy. ${ }^{12}$ Università degli Studi di Napoli Federico II, Napoli, Italy. ${ }^{13}$ Università Politecnica delle Marche, Ancona, Italy. ${ }^{14}$ Università Campus Bio-medico, Roma, Italy. ${ }^{15}$ Malzoni Center, Avellino, Italy. ${ }^{16}$ Università di Torino, Torino, Italy. ${ }^{17}$ A.O. S. Croce e Carle, Cuneo, Italy. ${ }^{18}$ Ospedale Sant'Andrea, Roma, Italy. ${ }^{19}$ Istituto Oncologico Veneto IOV-IRCCS, Padova, Italy.

Received: 15 November 2017 Accepted: 4 June 2018

Published online: 13 June 2018

\section{References}

1. Global Burden of Disease Collaboration. Global, Regional, and national cancer incidence, Mortality, Years of Life Lost, Years Lived With Disability, and Disability Adjusted Life-years for 32 cancer Groups, 1990 to 2015 A Systematic Analysis for the Global Burden of Disease Study. JAMA Oncol. 2017;3(4):524-48. 
2. AIOM, AIRTUM. I numeri del cancro in Italia. Roma: II Pensiero Scientifico Editore; 2016.

3. Bottomley A. The Cancer patient and quality of life. Oncologist. 2002;7:120-5.

4. Velikova G, Coensb C, Efficacec F, Greimeld E, Groenvolde M, Johnsong C, et al. Health-Related Quality of Life in EORTC clinical trials - 30 years of progress from methodological developments to making a real impact on oncology practice. EJC. 2012;Supplements 10(1):141-9.

5. Eton DT, Lepore SJ. Prostate cancer and health-related quality of life: a review of the literature. Psychooncology. 2002;11(4):307-26.

6. Penson DF, Litwin MS, Aaronson NK. Health related quality of life in men with prostate cancer. J Urol. 2003;169(5):1653-61.

7. Lane A, Metcalfe C, Young GJ, Peters TJ, Blazeby J, Avery KN, et al. Patientreported outcomes in the ProtecT randomized trial of clinically localized prostate cancer treatments: study design, and baseline urinary, bowel and sexual function and quality of life. BJU Int. 2016;118:869-79,

8. Noale M, Maggi S, Artibani W, Bassi PF, Bertoni F, Bracarda S, et al. Pros-IT CNR: an Italian prostate cancer monitoring project. Aging Clin Exp Res. 2017;29(2):165-72.

9. Gacci M, Livi L, Paiar F, Detti B, Litwin MS, Bartoletti R, Giubilei G, Cai T, Mariani M, Carini M. Quality of life after radical treatment of prostate cancer: validation of the Italian version of the University of California Los AngelesProstate Cancer Index. Urology. 2005;66:338-43.

10. Apolone G, Mosconi P, Quattrociocchi L, Gianicolo EAL, Groth N, Ware JJE. Questionario sullo stato di salute SF-12. Versione Italiana. Guerini e Associati Editore: Milano; 2001.

11. Hamoen EH, De Rooij M, Witjes JA, Barentsz JO, Rovers MM. Measuring health-related quality of life in men with prostate cancer: a systematic review of the most used questionnaires and their validity. Urol Oncol. 2015; 33(2):69.e19-28.

12. Conwell Y, Forbes NT, Cox C, Caine ED. Validation of a measure of physical illness burden at autopsy: the cumulative illness rating scale. J Am Geriatr Soc. 1993:41:38-41.

13. ISTAT Indagine "Aspetti della vita quotidiana" 2013 http://www.istat.it/it/ archivio/129956.

14. Choi EPH, Wong CKH, Tsu JHL, Chin WY, Kung K, Wong CKW, Yiu MK. Health-related quality of life of Chines patients with prostate cancer in comparison to general population and other cancer populations. Support Care Cancer. 2016;24:1849-56.

15. Krupski TL, Fink A, Kwan L, Maliski S, Connor SE, Clerkin B, Litwin MS. Healthrelated quality-of-life in low-income, uninsured men with prostate cancer. J Health Care Poor Underserved. 2005;16(2):375-90.

16. Singer MA, Hopmn WM, Mackenzie TA. Psychological adjustment in four chronic medical conditions. Qual Life Res. 1999;8:687-91.

17. Hopman WM, Harrison MB, Coo H, Friedberg E, Buchanan M, VanDenKerkhof EG. Association between chronic disease, age and physical and mental health status. Chronic Dis Can. 2009;29(3):108-16.

\section{Ready to submit your research? Choose BMC and benefit from:}

- fast, convenient online submission

- thorough peer review by experienced researchers in your field

- rapid publication on acceptance

- support for research data, including large and complex data types

- gold Open Access which fosters wider collaboration and increased citations

- maximum visibility for your research: over $100 \mathrm{M}$ website views per year

At BMC, research is always in progress.

Learn more biomedcentral.com/submissions 